\title{
Millimole per Liter per Microgram per Day
}

National Cancer Institute

\section{Source}

National Cancer Institute. Millimole per Liter per Microgram per Day. NCI Thesaurus. Code C119418.

A unit of concentration equal to millimoles per liter, divided by micrograms per day. 